\title{
Documento
}

\section{Moritz Thausing e a história da arte como ciência}

Moritz Thausing and the art history as a science

DOI: 10.20396/rhac.v2i2.15089

SERZENANDO VIEIRA NETO

Doutorando em História da Arte pela Universidade Estadual de Campinas (UNICAMP)

(1D) 0000-0002-8704-5724

\section{Resumo}

Em um contexto de profundas transformações nas disciplinas universitárias, Moritz Thausing (1838-1884) se coloca como um convicto defensor do estatuto científico da história da arte, sustentando a possibilidade de a jovem disciplina se apresentar como um campo sólido do conhecimento, baseado na estrita pesquisa empírica e na superação da especulação filosófica e dos juízos subjetivos. Apresentamos a seguir a tradução desse importante debate, uma conferência de 1873 intitulada O lugar da história da arte como ciência.

Palavras-chave: Moritz Thausing. Historiografia da arte. Fundamentos e crítica das artes.

\begin{abstract}
In a context of profound changes in university disciplines, Moritz Thausing (1838-1884) stands as a staunch defender of the scientific status of art history, sustaining the possibility of the young discipline to present itself as a solid field of knowledge, based on strict empirical research and in surpassing philosophical speculation and subjective judgments. We present the translation of this important debate, a conference of 1873 , entitled The status of art history as a science.
\end{abstract}

Keywords: Moritz Thausing. Art historiography. Fundamentals and critic of the arts. 


\section{Moritz Thausing e a história da arte como ciência}

Moritz Thausing nasceu em 1838 na pequena comuna boêmia de Čížkovice. Em 1857 iniciou seus estudos na Universidade de Praga, interessando-se primeiramente pela germanística e posteriormente pela história. Em 1858 transferiu-se para a Universidade de Viena, onde foi fortemente influenciado por intelectuais como Albert ]äger (1801-1891), Franz Pfeiffer (1815-1868), Rudolf Eitelberger (1817-1885). Em sua carreira Thausing transitou intensamente entre o meio universitário e o universo museológico. Sua primeira posição, assumida em 1862, foi como docente e bibliotecário da Academia vienense de artes plásticas [Wiener Akademie der bildenden Künste]. Em 1864 foi nomeado diretor da coleção de gravuras do arquiduque Albrecht [Albertina], sendo posteriormente nomeado inspetor (1868) e diretor (1876) dessa mesma instituição. Sua nomeação em 1873 como professor na Universidade de Viena marca o reconhecimento público do valor científico de suas pesquisas e atividades. Em 1884, com seu suicídio, interrompe-se sua breve e promissora carreira.

O trânsito facilitado no mundo das exposições e no meio universitário propiciava a Thausing uma posição privilegiada, uma acuidade singular na interpretação das controvérsias e debates que envolviam a arte da época. Essa característica é destaca por Anton Springer como uma notável vantagem:

Além disso, havia a posição invejável que Thausing ocupou em Viena. Ao combinar a direção independente de uma grande coleção de arte com o exercício livre do magistério, sua posição encarnava o ideal de um estudioso da arte. Como diretor da Albertina, Thausing desfrutou as alegrias de um colecionador de arte sem que precisasse experimentar suas consternações'.

A atuação na Albertina possibilitava não apenas o acesso privilegiado a um importante acervo de pinturas, mas também a ricas coleções de desenhos e gravuras. Foi justamente aí, na coleção de desenhos de Albert Dürer, que Thausing encontrou o objeto de pesquisa para sua obra-prima. A biografia de Dürer, publicada em $1876^{2}$, consagrou seu nome como um importante historiador da arte. O sucesso do livro foi imediato, como revelam as traduções que logo se seguiram; primeiramente para o francês (1878), pouco tempo depois para o inglês (1882). Segundo Springer, tratam-se de ricas contribuições à literatura francesas e inglesas, a divulgação e tradução da obra de um intelectual que pode ser visto como o "mais proeminente estudioso de Dürer" do século XIX³.

\footnotetext{
' SPRINGER, Anton. Moritz Thausing. Repertorium für Kunstwissenschaft, v. 8, 1885, p. 143.

${ }^{2}$ THAUSING, Moritz. Dürer: Geschichte seines Lebens und seiner Kunst. Leipzig: E. A. Seemann, 1876.

${ }^{3}$ SPRINGER, op. cit., p. 144, 147.
} 
Entretanto, em contraposição ao notável reconhecimento por parte de seus contemporâneos, Thausing ocupa um lugar marginal na literatura mais recente. Suas contribuições ao debate historiográfico e à fundação metodológica da história da arte, desvanecem-se diante do sucesso e proeminência dos intelectuais que atuaram em Viena em princípios do século seguinte, como Alois Riegl (1858-1905), Max Dvořák (1874-1921) e Julius von Schlosser (1866-1938)4.

O silêncio sobre o legado de Thausing, todavia, não representa um caso isolado. Em certa medida, acompanha o lugar marginal relegado aos historiadores da chamada "geração das grandes biografias artísticas"s. Esses historiadores, na medida em que se voltavam ao indivíduo e ao problema da objetividade na narrativa histórico-artística, tornaram-se pouco interessantes às discussões do século XX, que se concentrariam sobre o problema da forma e do estilo. Assim, ao lado de historiadores como Herman Grimm (1828-1901), Rudolf Eitel berger, Anton Springer (1825-1891), Carl Justi (1832-1912), Moritz Thausing pode ser visto como parte de um grupo de intelectuais que, apesar de terem sido cruciais para a fundamentação e institucionalização da disciplina, são hoje pouco lembrados. Esses historiadores tiveram como grande mérito a desvinculação da pesquisa histórico-artística do domínio da estética, consequentemente, a construção de uma sólida metodologia histórica, que se valia da pesquisa empírica e da superação da especulação e dedução filosófica.

As considerações de Thausing sobre a fundamentação da disciplina, seus escopos e métodos, são sintetizados em uma conferência de 1873, proferida como discurso inaugural de suas atividades docentes na Universidade de Viena. Intitulada O lugar da história da arte como ciência [Die Stellung der Kunstgeschichte als Wissenschaft], a conferência enumera os principais dilemas da história da arte e apresenta os caminhos que ela deveria percorrer para finalmente se estabelecer como disciplina de reputação científica equivalente a outros campos do saber, como a arqueologia e a história.

A exposição de Thausing divide-se em dois grandes repertórios. "A melhor história da arte na qual eu consigo pensar é aquela em que a palavra 'belo' simplesmente não tem lugar"; essas palavras sintetizam a primeira grande reflexão do autor, na qual se coloca como questão central a necessária distinção entre história da arte e estética, uma abordagem detalhada e comparativa de diferentes disciplinas universitárias procurando determinar seus pontos de interseções e cissuras. A segunda grande questão, à qual o autor se dedica, consiste na corriqueira confusão entre a prática artística e a compreensão teórica da arte. Na construção geral de seu argumento, Thausing tenta superar os erros

\footnotetext{
${ }^{4}$ A subestimação do papel de Thausing pela literatura especializada tem sido destacada por alguns autores, cf.: JOHNS, Karl. Moritz Thausing and the road towards objectivity in the history of art. Journal of art historiography, n. 1, 2009, p. 2. ROSENAUER, Artur. Moritz Thausing und die Wiener Schule der Kunstgeschichte. Wiener Jahrbuch für Kunstgeschichte, v. 36, 1983, p. 135. ${ }^{5}$ Referência à descrição de Heinrich Dilly, cf.: DILLY, Heinrich. Kunstgeschichte als Institution. Frankfurt am Main: Suhrkamp, 1979, p. 254 et seq.
} 
costumeiros que permeiam o debate sobre a arte, por vezes, transplantados para a jovem ciência, contaminando-a com toda espécie de juízos subjetivos. Sua conclusão é inequívoca, a prática artística pode ser vista como um complemento, mas jamais como algo necessário ao historiador da arte.

Com nossa tradução de O lugar da história da arte como ciência, baseada no original em alemão, apresentamos ao leitor brasileiro um texto que, a despeito de sua importância no contexto de fundação da disciplina ${ }^{6}$, permanece ainda pouco conhecido e pouco explorado. Com isso, nosso intuito não poderia ser outro senão fomentar o debate sobre a história da arte, enriquecendo-o com um documento crucial no contexto da gênese e fundamentação de seus métodos?

\section{O lugar da história da arte como ciência ${ }^{8}$}

O reconhecimento da mais nova história da arte $^{9}$ como disciplina científica, seu direito a ter lugar ao lado das outras disciplinas históricas, é algo recente. As opiniões sobre o seu significado ainda estão muito divididas. Sobre essa questão existem ideias totalmente estranhas, inclusive em círculos dos quais se poderia exigir um ponto de vista mais apurado. Portanto, não deveria parecer fora de propósito dedicar, primeiramente, alguma atenção à análise da extensão, do método e dos problemas relativos à pesquisa histórico-artística. Na minha opinião, a melhor maneira de atingir esse objetivo é através de um caminho indireto, contemplando as fronteiras que separam ou unem a história da arte e as ciências correlatas (arqueologia clássica, estética, história universal); e, finalmente, aquele importante limite que

\footnotetext{
${ }^{6}$ Não poderíamos deixar de destacar a clara correlação entre a conferência de Thausing e as questões apresentadas por Anton Springer em Peritos em arte e historiadores da arte [Kunstkenner und Kunsthistoriker], cf.: SPRINGER, Anton. Kunstkenner und Kunsthistoriker. Im neuen Reich, v. 27, 1881, p. 737-758. O texto de Springer foi recentemente traduzido para o português, cf.: VIEIRA NETO, S. A. Peritos e historiadores da arte. Figura, v. 8, n.1, 2020, p. 321-358. A despeito do intenso debate sobre a relação da história da arte com as disciplinas correlatas, tal questão não parece ter sido superada, como podemos perceber na breve retrospecção de Dehio, cf.: DEHIO, Georg. Das Verhältnis der geschichtlichen zu den kunstgeschichtlichen Studien. In: Kunsthistorische Aufsätze. München; Berlin: Roldenbourg, 1914, p. 245-246.

${ }^{7}$ O lugar da história da arte como ciência conta hoje com uma tradução para o inglês, publicada por Karl Johns, cf.: JOHNS, op. cit. O leitor interessado encontrará algumas referências iniciais para o estudo da vida e obra de Thausing nos seguintes títulos: EITELBERGER, Rudolf. Moritz Thausing. Wiener Zeitung, n. 197, 1884, p. 4-6; FEIST, Peter. Moritz Thausing. In: Metzler Kunsthistoriker Lexikon. $2^{\text {a }}$ ed. Stuttgart; Weimar: Metzler, 2007, p. 433-434; ROSENAUER, op. cit; SPRINGER, op. cit.

8 Publicado originalmente como: THAUSING, Moritz. Die Stellung der Kunstgeschichte als Wissenschaft: aus einer Antrittsvorlesung an der Wiener Universität im Oktober 1873. Oesterreichische Rundschau, 1883. Reproduzido no ano seguinte como: THAUSING, Moritz. Die Stellung der Kunstgeschichte als Wissenschaft. In: Wiener Kunstbriefe. Leipzig: E. A. Seemann, 1884, p. 1-20.(Nota do tradutor)

${ }^{9}$ No original, neuere Kunstgeschichte. O termo, que não possui correspondente preciso no português, é traduzido de forma literal como "mais nova história da arte". Ele se refere a toda produção artística do século XV em diante, implicando, nesse contexto, na concepção da arte da Idade Média e da Antiguidade como campos de estudo distintos. Neuere Kunstgeschichte aparece em importantes referências da época, como a coletânea de ensaios de Anton Springer, Bilder aus der neueren Kunstgeschichte (1867), ou o artigo de Julius von Scholler, Die Bedeutung der Quellen für die neuere Kunstgeschichte (1892). (Nota do tradutor)
} 
separa a história da arte do exercício artístico prático, que não é nada além de um profundo abismo que surge em toda parte entre teoria e práxis.

A mais nova história da arte possui uma íntima relação com a arqueologia clássica; ela é, por assim dizer, sua irmã mais nova. Seu objeto representa a própria continuidade da arqueologia. Com ela, a história da arte tem em comum a natureza dual das fontes, o tipo de método, o ponto de chegada. Ambas as disciplinas se relacionam graças à estreita correlação de seu assunto e à propagação das formas especialmente das arquitetônicas - de um período histórico nos períodos subsequentes. De fato, as duas disciplinas simplesmente compõem diferentes etapas de uma mesma ciência e serão mantidas separadas somente porque o indivíduo dificilmente pode atender totalmente às exigências de ambas as áreas. Assim, ao lado de todo traço comum, características majoritariamente internas, subsistem várias diferenças externas. As fontes da arqueologia são outras; no número medido ou pelo menos mensurável de seus monumentos, a aplicação do método é diferente, incomparavelmente mais intensiva; isso é possível porque ela possui um sólido apoio na filologia clássica. Ao lado disso, encontra-se presente o profundo interesse pelos objetos da arqueologia clássica, já que o espírito alemão está há muito habituado a buscar no espírito da Antiguidade clássica a sua força ${ }^{10}$. Por isso a arqueologia encontrou seu estabelecimento e adaptação muito antes da mais nova história da arte; a arqueologia obteve prematuramente seu lugar e sua voz na universitas litterarum, ao longo de aproximadamente duas gerações.

Pois bem, assim como a germanística e a filologia românica se esforçam para alcançar a filologia clássica, assim como a história mais recente se esforça para alcançar a história da Antiguidade, a mais nova história da arte procura se situar ao lado da arqueologia, afirmando-se como uma irmã de prestígio equivalente. Com efeito, a história da arte empreendeu apenas sua tentativa inicial de alcançar esse fim; a primeira geração de professores de história da arte ainda está atuante. Um de seus fundadores, o patriarca Schnaase ${ }^{11}$, faleceu em 1875. Considerando o curto espaço de tempo de sua existência e as condições desproporcionalmente menos favoráveis, a jovem ciência alcançou o suficiente. Futuramente isso será reconhecido, quando se olhar para atrás, para os princípios da história da arte. Com isso, o campo de sua pesquisa parece muito alargado, provisoriamente, quase sem fronteiras. $O$ estoque de seus

\footnotetext{
${ }^{10}$ A ideia da íntima conexão espiritual entre a Alemanha e a Antiguidade clássica era bastante difundida no século XIX. Por vezes, carregava uma certa concepção de superioridade cultural. Este trecho de Gervinus nos oferece um bom exemplo: "Se classificássemos as massas principais da história europeia desse modo, então, simultaneamente, teríamos identificado que, na verdade, existem apenas três povos que formam o núcleo de toda a história (...). Apenas gregos, italianos e alemães nunca tiveram uma formação política rigorosa, mas, em contrapartida, uma formação puramente humana, tendo sido eles os verdadeiros cultivadores da arte e da ciência; somente eles que produziram historiadores verdadeiramente grandes", cf.: GERVINUS, Georg Gottfried. Fundamentos de teoria da história. Petrópolis: Vozes, 2010 [1837], p.73. (Nota do tradutor) ${ }^{11}$ Karl Schnaase (1798-1875), historiador da arte e autor das famosas Niederländische Briefe (1834). (Nota do tradutor)
} 
monumentos é subjugante. O estudo das fontes não foi preparado pela história recente e pela história da literatura do mesmo modo que a filologia preparou para a Antiguidade. Esse estado de coisas exige um tratamento cauteloso, uma utilização extensiva do método, para que a unidade da disciplina não seja comprometida pela parcialidade. O interesse mais geral pelos objetos da moderna pesquisa artística é frequentemente mais danoso do que proveitoso, está relacionado com questões práticas, contando com o ódio e a graça dos diferentes partidos ${ }^{12}$.

Ocasionalmente, entretanto, também os propósitos extra-científicos, as considerações práticas, os ramos particulares da ciência da arte, mostram-se úteis, por exemplo, a arqueologia medieval, especialmente a eclesiástica, que se apresenta como uma espécie de contraponto romântico à ciência da arte clássica. Havia um tempo em que imperava uma certa confusão; se o interesse recaía sobre o próprio santo ou simplesmente sobre sua imagem, se as relíquias estavam sendo enfatizadas em função das próprias relíquias ou de seu significado. Através disso, a arqueologia medieval foi materialmente promovida, mas não no que se refere à sua consolidação formal enquanto disciplina científica.

Para outros períodos, especialmente para o Renascimento tardio, tornou-se habitual o tratamento estético da história da arte. Tem-se um certo apreço pela conexão contínua e direta com conceitos totalmente gerais, mais ou menos inexplicados, por um cânone de beleza aleatório, que, admitido ou inconsciente, é tomado geralmente da Antiguidade, por vezes, também de Rafael. Esse direcionamento da escrita sobre a arte, ainda muito comum, compara-se com a findada fase da influência da filosofia natural sobre a história legal e as ciências naturais. É cultivado principalmente por artistas ou personalidades voltadas à arte, que tomam um caminho semelhante ao daqueles que chegam a um entendimento mais subjetivo das formas artísticas e dos monumentos. Em razão das regras de gosto préconcebidas, eles examinam as obras de arte de arte simplesmente para atribuir a elas, utilizando-se das melhores palavras possíveis, o correspondente grau de suas satisfações ou insatisfações pessoais. A maioria daqueles que escrevem sobre a arte não estão familiarizados ou não consideram o fato de que tais juízos de gosto sempre possuem um valor relativo, alteram-se em sua essência com o passar do tempo.

\footnotetext{
${ }^{12}$ Acaloradas disputas a respeito da autoria de algumas obras marcavam o pano de fundo do texto de Thausing. A "disputa sobre Holbein" [Holbein-Streit] é um exemplo característico da divisão de opiniões em dois partidos irreconciliáveis e a introdução de interesses diversos na crítica artística. Sobre o referido episódio, cf.: BÄTSCHMANN, Oskar. Der Holbein-Streit. Jahrbuch der Berliner Museen, v. 38, 1996, p. 87-100; PRANGE, Regine. Die Geburt der Kunstgeschichte. Köln: Deubner, 2004, p. 174 et seq. Como podemos ver no relatório de Lützow, Moritz Thausing teve participação na série de conclusões a respeito da autenticidade da Madonna de Darmstadt, mostrando uma atuação prática naquilo que é descrito de forma teórica na conferência de 1873, cf.: LÜTZOW, Carl. Ergebnisse der Dresdner Holbein-Ausstellung. Zeitschrift für bildende Künste, v. 6, 1871, p. 355. (Nota do tradutor)
} 
Chegamos agora a outra fronteira da história da arte, a saber, aquela em que ela toca a estética e dela se afasta. De maneira totalmente indevida essas duas ciências são tomadas em conjunto, já que são completamente distintas em seus métodos e problemas. A história da arte não tem nada em comum com a estética enquanto disciplina filosófica, aliás, nada além do que a história política tem em comum com a filosofia moral, a fisiologia com a psicologia, a história natural com a metafísica, isto quer dizer, a história da arte fornece à estética uma parte considerável de seu material para o subsequente tratamento filosófico, entretanto, se ela faz uso desse material ou não, isso não diz respeito à pesquisa históricoartística. A história da arte não está de forma alguma autorizada a, por sua parte, adentrar no domínio da filosofia e utilizar, para os seus propósitos e sua exposição, fórmulas estéticas ou expressões provenientes de qualquer sistema. Ela não tem nada a ver com a dedução, menos ainda com a especulação; o que ela deseja promover não são juízos estéticos, mas sim fatos históricos, os quais podem servir como material para uma pesquisa indutiva. Da mesma forma que a história política não tem como propósito proferir juízos morais, a história da arte não tem como medida os parâmetros estéticos. Esses parâmetros não são, de forma alguma, absolutos, mas são simplesmente relativos, orientam-se pelo direcionamento ascendente ou descendente da evolução artística de uma época. Por exemplo, não se justifica na história da arte a pergunta a respeito da beleza de uma pintura. É um verdadeiro absurdo para a história da arte perguntar se foi Rafael ou Michelangelo, Rembrandt ou Rubens, o artista a alcançar o maior grau de perfeição. A melhor história da arte na qual eu consigo pensar é aquela em que a palavra "belo" simplesmente não tem lugar. O juízo histórico-artístico se fundamenta apenas nos fatores averiguados pela pesquisa e análise crítica, sob os quais uma obra de arte surgiu. Nós respondemos às perguntas sobre a relação entre a habilidade de uma artista e a sua intenção, sobre a relação entre ambas e o material que ele manuseia, simplesmente através da comparação com seus contemporâneos, predecessores e sucessores, ou seja, sem o suporte de qualquer parâmetro estético geral.

A abordagem estetizante se tornou um grande inconveniente para a evolução, bem como para a boa reputação da história da arte, uma disciplina que mal acabou de ser efetivamente estabelecida. $\mathrm{O}$ juízo e a classificação tiveram que ser rapidamente finalizados, ignorando tantas mediações, trazendo consigo a maldição da esterilidade; por outro lado, esse procedimento sumário não foi adequado para despertar em pensadores sérios conceitos elevados sobre o método e a disciplina da história da arte. Promove-se muito mais a difusão daquela visão segundo a qual a história da arte é apenas uma forma de entretenimento intelectual - uma espécie de guloseima que traz consigo o perigo da indigestão intelectual -, e não um alimento intelectual saudável, um campo de trabalho árduo e gratificante, como todas as outras áreas científicas. Assim, acontece que é mais do que necessário que a história da arte seja 
colocada ao lado da estética e, por conseguinte, ainda mais necessário, que sejam enfatizadas as fronteiras que as separam, as características que as distinguem, e não as suas correlações.

A situação é diferente quando se trata da relação de nossa ciência com um terceiro objeto do estudo universitário; uma relação sobre a qual eu devo colocar o mais alto valor, a saber, a relação com a história geral da Idade Média e dos tempos mais recentes. Nessa relação é válido colocar mais ênfase nos aspectos que unem do que nos que diferenciam. Em relação à arqueologia, a história da arte se comporta como sua sucessora; em relação à estética, como sua percussora ou antecipadora; já em relação à história, como uma eterna companheira, um complemento necessário, uma parte indispensável. Na verdade, não me refiro à história no sentido estrito da história dos Estados, dos regentes e das guerras. Há muito tempo essa tem sido considerada a única história válida, uma concepção que ainda hoje é dominante. Ao contrário, refiro-me àquela compreensão mais geral que aponta para o conjunto da vida espiritual, para todas as formas da moralidade, para o Estado, religião, literatura e arte. Desta forma, ela se torna história do povo, história da cultura no bom sentido, ou seja, naquele sentido estabelecido também por Böckh em seu conceito geral de filologia ${ }^{13}$. Se essa filologia abrange o estudo da linguagem, o conhecimento literário, a arqueologia e a história, as antiguidades e as leis antigas, o que mais ela seria senão a ciência do homem espiritual, senão aquilo que poderíamos denominar história da cultura, caso esse nome não estivesse desgastado pelo mau uso? Palavras diferentes para o mesmo objetivo! Porque apesar de todos os protestos dos políticos históricos, a história sempre dará maior ênfase a uma abordagem universal no estudo e investigação dos monumentos culturais da tradição - sobretudo em um período cujos maiores homens de Estado contestam, partindo dos seus próprios pontos de vista, a divisão conceitual de governo e povo, almejando que os regentes sejam incluídos na categoria do povo. Assim, a história política deverá sempre trazer para o seu domínio a vida dos povos, ou seja, em especial, o desenvolvimento interno daquelas nações que são merecedoras da cultura moderna. De acordo com esse último ponto de vista, a história tem balizado os limites daquilo que merece ser examinado. Admitindo isso, a história da arte, sobretudo da arte medieval, constitui um ramo da mais nova ciência histórica, assim como a arqueologia constitui um ramo da filologia, que se estende ao estudo da Antiguidade - com efeito, um ramo muito importante e essencial, desde que se apresente como verdadeiro conhecimento das respectivas condições culturais de um povo.

\footnotetext{
${ }^{13}$ August Böckh (1785-1867), filólogo clássico e antiquário. Para Böckh a filologia consistia no estudo do conjunto da produção espiritual do homem, aquilo que o autor define conceitualmente como "reconhecimento do que é conhecido" [Erkennen des Erkannten], cf.: BÖCKH, August. Encyclopädie und Methodologie der philologischen Wissenschaften. Leipzig: Teubner, 1877, p. 10. (Nota do tradutor)
} 
A peculiaridade da história da arte e, paralelamente, a dificuldade característica em seu tratamento, reside nos dois tipos de fontes, totalmente distintos, dos quais ela extrai seus resultados. Por um lado, existem as mensagens escritas, a exemplo das epígrafes, certidões, cartas, escritores, ou seja, testemunhos que estão totalmente sujeitos às regras habituais da crítica histórica e que delas necessitam, como as fontes da história geral e da história política dos Estados. Diante desses testemunhos literários ou documentais encontra-se o outro grupo de nossas fontes de conhecimento, os monumentos, memoriais e obras de arte, que representa, ao mesmo tempo, o objeto principal de nossa pesquisa. Incontestavelmente essas fontes são tidas como o legado mais precioso que o passado nos transmitiu. Da mesma forma que os documentos falam por meio de palavras, os monumentos falam por meio de formas visíveis. A tarefa da história da arte consiste em aprender a ler e interpretar de maneira correta essa linguagem. Quando ela ilumina as imagens de períodos culturais passados, apresenta-se como uma poderosa ferramenta para o correto conhecimento e apreciação dos mesmos. A maioria de nossas concepções e conceitos está ligada às impressões da percepção visual. Nesse sentido, portanto, elas serão passíveis de correção (de fato, precisarão). Nossos monumentos artísticos, entretanto, não nos oferecem apenas meras ilustrações do passado, ilustrações documentais, correções para a nossa infatigável imaginação. Eles nos fornecem simultaneamente um saber inconfundível sobre o modo como uma época passada pensava e sentia, sobre o conjunto da potência intelectual que a predispunha. Partindo principalmente desse ponto de vista, a história da arte é uma ciência auxiliar da história geral, de fato, uma auxiliar imprescindível. Com razão, o maior filólogo e historiador da Antiguidade vivo, Theodor Mommsen ${ }^{14}$, considera absurdo escrever a história de um povo cuja linguagem não se compreende. Ora, a arte de um povo é também uma linguagem. Seus monumentos são como destacados indicadores de milhas que guiam o olhar indagador em direção ao caminho pelo qual uma nação foi, através de séculos e milênios, conduzida por seu gênio. Sim, eles nos guiam por épocas em que as fontes escritas ainda não eram recorrentes e que, por isso, são chamadas de pré-históricas (de forma indevida, penso eu). A linguagem desses testemunhos não-escritos é mais ideal, mais imparcial, mais livre de impressões subjetivas e casualidades externas, do que qualquer outro testemunho escrito. Sua compreensão pode ser mais difícil, todavia, não pode ser mal interpretada; uma vez que essa linguagem é dominada, ela pode, sobretudo, proteger-nos. Sim, proteger a nós historiadores da acusação frequentemente justa que o poeta vestiu com as seguintes palavras:

\footnotetext{
${ }^{14}$ Theodor Mommsen (1817-1903), historiador e especialista na história da Antiguidade latina. (Nota do tradutor)
} 
Aquilo que chamais de espírito das épocas,

é, no fundo, o vosso próprio espírito,

sobre o qual as épocas se refletem ${ }^{15}$

Entender a linguagem dos registros literários e dos documentos, investigar a autenticidade e significado dos mesmos, já é uma ciência. Quanto mais uma ciência precisará para se aprofundar na compreensão dos monumentos e patrimônio artístico. Esse caminho será necessariamente longo e árduo. Não se deve exigir muito de seu progresso. Nossa disciplina não pressupõe um talento singular e excepcional, como acontece com a produção artística. Penso que a história da arte demanda de seus jovens simplesmente aquele grau de formação geral, aquele vigor de sentido, da mesma forma que, no geral, é indispensável para o cultivo eficaz de qualquer outro campo do saber exato. Os juízos de nossa disciplina não se guiam por um método heterodoxo ou totalmente obscuro. Os entraves para o seu desenvolvimento são, na verdade, de natureza externa. Geralmente esses entraves consistem na dificuldade limitante, quase impossibilidade, de se obter uma visão geral do acervo de monumentos e de se conservar na memória os seus detalhes. Nosso estudo se baseia, sobretudo, na visão apurada dos monumentos. E para se chegar a esse conhecimento não é necessária nenhuma inspiração especial ou divinação. Ao contrário, é muito mais um caminho que se pauta pelo rigoroso exame e contínua comparação, de forma semelhante àquele que a mais prática de nossas ciências, as ciências naturais, introduz e cultiva. Em relação às ciências naturais nos encontramos em uma grande desvantagem, isso porque o objeto artístico não pode ser acessado da mesma forma que os objetos da natureza e porque para nós, definitivamente, não existe nenhum experimento, menos ainda, um corpus vile.

Naturalmente, tudo o que dizemos sobre os dois tipos de fontes do nosso conhecimento também é válido para a arqueologia. De forma gradual, a arqueologia tem trazido para o domínio de sua pesquisa a integralidade dos monumentos artísticos disponíveis da Antiguidade. Ninguém pensa em colocar em dúvida sua competência para tratar desses assuntos. O caso é totalmente diferente com a mais nova história da arte. Não é fácil dar cabo à imensa massa de material que se apresenta à história da arte. Ela trabalha arduamente na delimitação de seu domínio; luta simplesmente pelo reconhecimento mais geral, luta pelo direito àquela grande divisão limítrofe, que geralmente se reconhece para o bem de todas as outras ciências, qual seja, o limite que separa teoria e práxis. Quem não iria rir diante da ideia de que um escultor, enquanto tal, reclamasse para si o direito de proferir juízos sobre a origem ou originalidade de uma escultura antiga? Que desejasse que Ihe confiassem a supervisão ou ordenação de uma coleção

\footnotetext{
${ }^{15}$ Thausing faz referência a uma passagem da cena Noite, do primeiro volume do Fausto de Goethe. Na edição brasileira, cf.: GOETHE, J. W. Fausto: uma tragédia - primeira parte. São Paulo: Editora 34, 2004, p. 72. (Nota do tradutor)
} 
de esculturas, ou mesmo de réplicas de gesso? Não se iria rir diante da ideia de promover um puncionador a diretor de uma coleção de moedas? Ao contrário, em muitos lugares, de forma totalmente natural, pintores ocupam altas posições nas galerias. Da boca de muitos instruídos escuta-se sempre o repetido erro grosseiro, já apontado por Rumohr, de que somente o pintor saberia julgar uma pintura ${ }^{16}$. A indefinição dessa divisão limítrofe acarreta muitas desvantagens para nossa ciência, não apenas na opinião da massa, mas também em nossa própria atividade. A indefinição faz com que confundamos nossos direitos e obrigações; ela nos desvia do estudo fundamental dos monumentos e faz com que muitos de nós se contentem com as comparações literárias.

Se fosse verdade que apenas o gravador pudesse julgar uma gravura, o pintor uma pintura antiga, o escultor de marfim um díptico, o oleiro um vaso antigo, então, com efeito, não existiria nenhuma ciência da arte, nenhuma história da arte. Todavia, especialmente quando se trata de obter novas forças para nossa disciplina, deve ser sempre dito que essa hipótese é totalmente falsa e injustificada. Por conseguinte, como alguém, na qualidade de professor, poderia responder, despertar em outro o desejo de seguir um campo do conhecimento imperfeito, que não foi capaz nem mesmo - como nós rotineiramente escutamos - de se tornar independente de atividades práticas, um campo do conhecimento cujas melhores e derradeiras verdades nos encobrem em um véu impenetrável que só pode ser retirado pelas mãos daquele que se dedica à prática? Vamos nos acalmar. A história da arte não é tão ruim. Aos poucos todo mundo chegará ao entendimento de que a mão sempre seguiu o olho, mas o olho nunca seguiu a mão. Desejar se instruir sobre uma pintura antiga com um pintor moderno não é menos tolo do que desejar que um diplomata nos ministre aulas sobre documentos antigos. Em ambos os casos o presente e o passado se separam completamente e o conhecimento desse último permanece, de forma exclusiva, objeto da ciência.

Mais do que isso! Práxis e teoria não devem ser meramente diferenciadas. Elas formam também uma oposição definitiva, correspondem a dois caminhos completamente opostos através dos quais o homem chega ao conhecimento de um objeto. Um caminho é o da imitação, através de uma soma de habilidades aprendidas; o outro é o caminho da investigação científica, através da observação, experimentação e comparação. Agora, de fato, é inevitável que ambas as atividades se cruzem aqui e ali,

\footnotetext{
${ }^{16}$ Cf.: RUMOHR, Carl. Italienische Forschungen. Vol. 3. Berlin; Stettin: Nicolaische Buchhandlung, 1831, p. 148-154. Na conclusão do trecho: "Portanto, quem tem o direito de decidir onde se aplica o geral, o puramente humano? Certamente não o sócio de uma corporação, esteja ele em uma posição baixa ou elevada de uma oficina, mas sim o homem mais ingênuo, mais puro, mais sensato, seja ele um artista ou oriundo de qualquer outra profissão. Todo valor, a força revigorante de um tal louvor, só pode ser efetivamente medido por artistas que já tiveram a felicidade de elevar e alegrar pessoas ingênuas e sensíveis por meio da cla ra evocação de tarefas respeitáveis. Aliás, a história ensina que uma ampla predisposição popular é a primeira condição para um desenvolvimento proveitoso da arte. Em contrapartida, uma arte para a mera satisfação dos artistas é um absurdo inaudito". (Nota de Thausing)
} 
às vezes inibindo uma à outra, às vezes se apoiando mutuamente. Os escopos de sua aspiração são de naturezas tão distintas que jamais pode se pensar em uma coincidência de resultados.

$\mathrm{O}$ artista instrui o seu olho, por assim dizer, por meio da mão. Aquilo que ele aprende em longos anos de prática não é a arte em sua generalidade, mas sim sua própria arte, uma concepção das formas que lhe é totalmente singular, que Ihe torna cego ou, aliás, totalmente parcial, para todas as outras concepções. No vizinho ele já não se sente em casa, muito menos em um tempo longínquo, no qual prevalecia tradições e técnicas que foram completamente interrompidas. Naturalmente, eu me refiro aqui apenas ao artista tolo, que é digno desse predicado. De um tal artista pensante e consciente de seus objetivos podemos aprender algo de sua própria criação e de seu processo técnico, o que pode então possibilitar uma aplicação teórica adaptada, mais geral. Normalmente, entretanto, esse artista tem coisas melhores a fazer do que competir pelo preço do conhecimento artístico e se preocupar com seus colegas e percussores de profissão. Ao contrário, os talentos medianos, que frequentemente fazem isso, não conseguem nem mesmo desenvolver uma concepção própria das formas. Faltam-Ihes aquelas lentes subjetivamente coloridas através das quais artistas chegam, senão a juízos corretos, a juízos artísticos espirituosos ou originais. Desses, nós não podemos aprender nada.

Certamente há que se distinguir os artistas praticantes daqueles homens que inicialmente procuram exercer a atividade artística, mas que logo se desviaram desse caminho, dedicando-se, desde então, exclusivamente aos estudos teóricos da arte. Com isso, certamente eles irão fazer proveito de seus prévios exercícios práticos, todavia, os mesmos não são, de forma alguma, indispensáveis. Para se aprender a apreciar e compreender uma obra das artes plásticas, não é necessária uma reprodução repetitiva, como ocorre com as peças musicais. A obra imagética está definitivamente pronta e demanda para sua apreciação nada além da atenta observação. É uma visão inteiramente comum que para se chegar a um juízo sobre uma obra das artes visuais, também deve se tentar produzi-la. Essa afirmação, que se propaga de maneira tão irrefletida, contém uma exigência injusta para o mundo da produção artística, uma espécie de mortificação do direito geral da pesquisa científica. Enquanto nós, historiadores da arte, expressamente tirarmos proveito desse direito, não há nenhuma outra forma de conhecimento senão o caminho da teoria. Nossa tarefa consiste em instruir nosso olho sem dar atenção ao treinamento específico da mão. Com efeito, desejamos simplesmente aprender a ver.

De fato, isso não é tão fácil como parece. O homem natural e a criança recebem impressões muito imperfeitas daquilo que observam. Originalmente, não é tanto a mão, mas sim o olho do homem que é inábil. Foram necessários milênios, uma lenta prática no caminho da arte, para que o homem desenvolvesse sua atual sensibilidade. Aos antigos japoneses, indianos ou irlandeses, que construíam e 
movimentavam as figuras humanas de modo inadequado, não faltava, de forma alguma, perícia com as mãos, haja vista os incontáveis exemplos de seus mais finos e difíceis trabalhos (testificando justamente o contrário). Faltavam-Ihes apenas as experiências do olho, as quais foram adquiridas pouco a pouco somente em épocas posteriores. A espécie humana aprendeu gradualmente a olhar, assim como teve que aprender gradualmente a ouvir de modo mais refinado e a se comunicar de maneira mais precisa. $\mathrm{Na}$ verdade, em cada uma das duas grandes culturas que primeiramente nos interessa, a da Antiguidade e da época mais recente, foi necessário quase que começar tudo de novo, ou pelo menos, empreender novas tentativas. O desenvolvimento do sentido cromático nos oferece um exemplo especialmente instrutivo. Quanto tempo levou para que homem simplesmente pudesse ver as cores do arco-íris, aprendesse a diferenciá-las! Nem o Rigueveda, nem o Zendavesta, nem a Bíblia, conheciam, por exemplo, a cor azul ${ }^{17}$. Em todos esses, o azul ainda coincidia com o conceito de cor preta. Supostamente, o mesmo é válido para a palavra kyaneos em Homero, apesar do nosso ciano derivar daí. Toda a Antiguidade não possuía uma palavra para o azul puro, já que o caeruleus também não pode ser considerado. A classificação da cor verde também não se encontrava em uma situação muito melhor. Da mesma forma, os mais antigos documentos persas e sânscritos não trazem referências. Entre os gregos, o chlóros mal pode ser diferenciado do amarelo óchros. Como não podia faltar motivos para chamar o céu e o mar de azul, as árvores e as várzeas de verde, encontramos aqui um inequívoco daltonismo parcial, que só poderia resultar de uma falta de distinção. Da mesma forma, o fato de as línguas primitivas se restringirem a três vogais - a, i, u-, em contraposição à formação tão rica de vocalismos de uma língua como o inglês atual, só pode ser explicado pela insuficiência de treinamento auditivo ${ }^{18}$.

Esse lento desenvolvimento do sentido cromático encontra sua analogia também na descoberta tardia das leis da harmonia musical. Em vista disso, tanto a pintura, quanto a música, somente puderam chegar ao seu auge nas épocas mais recentes. Ambas são artes especificamente modernas. Que grande prova de força a visão e a audição tiveram que superar, antes que uma pintura de Rembrandt, uma sinfonia de Beethoven, pudesse surgir e ser apreciada! Os antigos não poderiam ter absolutamente qualquer ideia do auge de ambos os desenvolvimentos artísticos, da mesma forma que hoje nós não

\footnotetext{
${ }^{17}$ Referência aos livros sagrados de três antigas tradições religiosas, respectivamente, hinduísmo, zoroastrismo e judaísmo. A discussão sobre a percepção das cores e a incapacidade do homem, em seus primórdios, de perceber e descrever certos fenômenos, foi levantada pelo filólogo Lazarus Ceiger, cuja argumentação embasa integralmente a apresentação de Thausing, cf.: GEIGER, Lazarus. Zur Entwicklungsgeschichte der Menschheit. $2^{\text {a }}$ ed. Stuttgart: Cotta, 1878, p. 46 et seq. (Nota do tradutor) ${ }^{18} \mathrm{Ibid}$., p. 45 et seq. É verdade que Aristóteles classifica o arco-íris como tricolor, especificamente, vermelho, amarelo e verde (como também a Edda, que o define como uma ponte tricolor), enquanto Xenófanes, duzentos anos antes, via no arco-íris simplesmente uma nuvem púrpura, vermelha e amarela. Demócrito e os pitagóricos admitiam quatro cores fundamentais: preta, branca, vermelha e amarela; uma visão que se manteve válida por muito tempo. Informações presentes em Cícero, Plínio e Quintiliano nos levam a acreditar que os pintores gregos, até o tempo de Alexandre, utilizaram apenas essas quatro cores. (Nota de Thausing)
} 
compreendemos seu início humilde. Nisso reside seguramente a razão para que nós, partindo do ponto de vista de nossa percepção cromática treinada e refinada, jamais possamos nos familiarizar com a simplicidade policrômica dos antigos.

Assim ocorreu o aperfeiçoamento do sentido da visão humana, em um processo que durou milênios. Aconteceu a serviço da arte e para os seus propósitos, fosse ela às vezes compreendida como inerte ou declinante. Aconteceu em uma época em que não havia história da arte. A arte continuará a evoluir e a retroceder de acordo com leis inexplicáveis, que não se submetem aos nossos esforços científicos. Nós, historiadores da arte, ainda estamos longe de arrogar qualquer influência sobre a prática artística. Entretanto, depois que se tornou irrefutável a necessidade da investigação de nosso passado artístico, deixe-nos também nos mover no campo histórico que nos compete. Nós desejamos esse campo por completo, nivelá-lo e cultivá-lo; também por amor aos artistas que com grande estima a ele se dedicam. Aliás, aos artistas essa terra permaneceria encoberta, caso eles não se apoderassem de sua teoria. Por um século, passados a Antiguidade e o Cinquecento, os artistas se mudaram para a Itália para regressarem desinformados e não convertidos, até que Winckelmann revelou-Ihes a Antiguidade e Rumohr redescobriu o Renascimento.

Ao olho do historiador da arte são feitas exigências totalmente diferentes, muito mais gerais e abrangentes do que as exigências colocadas ao olho do artista. Nossa forma de ver, portanto, deve ser completamente distinta, uma vez que tem como propósito exclusivo o conhecimento do objeto, sem qualquer restrição por concepções formais pré-estabelecidas e sem quaisquer intenções secundárias quanto à reprodução e execução prática. Para alcançar um objetivo é preciso, pelo menos, ir em frente com determinação. Assim, além disso, não se pensará em alcançá-lo, ainda que fosse um objetivo menos elevado. Nossa ciência já nos ofereceu prova suficiente de que sua prossecução sobre nosso caminho puramente teórico é possível. Sobre o grau de segurança que o olhar do conhecedor pode desenvolver sob circunstâncias propícias, temos diante de nós, em naturezas singulares privilegiadas, elevados exemplos.

Portanto, não nos assustemos com as curiosas expressões e invocações com as quais as obras de artes costumam ser tratadas. Com efeito, o indivíduo, em certo sentido, deve repetir o curso do desenvolvimento de todo o gênero humano. Nosso olho também deve, seguindo o conjunto da evolução artística do passado, treinar sua capacidade visual em busca do maior refinamento possível. Encontramonos aí diante de uma grande tarefa que não é de forma alguma impossível. Não há qualquer alma, qualquer espírito, qualquer sentimento em uma obra de arte que não seja marcada por formas visíveis totalmente concretas e que, por isso, não seja também vista em um caminho claro e nítido, interpretada a partir de si mesma. Na verdade, somente deve-se aprender, arduamente vale dizer, essa linguagem das 
formas artísticas, assim como todas as linguagens. Considerando o talento e a oportunidade de praticar, talvez nem todos alcancem o domínio adequado. Entretanto, obteremos sucesso se alcançarmos um grau no qual os traços de todo grande artista deixem de ser para nós um enigma. Podemos, então, arrojadamente adentrar em sua obra, tendo em mente as belas palavras proferidas por um amigo muito estimado, um perito em arte, Ivan Lermolieff' ${ }^{19}$ :

Uma obra de arte sempre te dará uma resposta correta, quando você souber como perguntá-la. Se a resposta lhe parece insuficiente, isso é apenas um sinal de que, ou sua pergunta foi mal formulada, ou a obra não possui absolutamente nenhuma linguagem,

ou seja, não é uma autêntica obra de arte.

\section{Die Stellung der Kunstgeschichte als Wissenschaft ${ }^{20}$}

Die Anerkennung der neueren Kunstgeschichte als wissenschaftliche Disciplin, ihre Berechtigung, neben den anderen historischen Fächern Platz zu nehmen, ist noch jungen Datums und die Meinungen über ihre Bedeutung sind noch sehr getheilt. Es bestehen in dieser Hinsicht zum Theile gar wunderliche Vorstellungen, auch in Kreisen, denen man einen gewählteren Standpunkt in dieser Frage wohl zumuthen könnte. Es dürfte daher zunächst nicht unzweckmässig erscheinen, über Umfang, Methode und Probleme der kunstgeschichtlichen Forschung einige Rechenschaft zu geben. Und zwar gelangen wir meines Erachtens zu diesem Ziele am besten auf einem indirecten Wege, indem wir nämlich die Grenzen in's Auge fassen, welche die Kunstgeschichte von den verwandten Wissenschaften, als da sind die classische Archäologie, die Aesthetik und die Weltgeschichte, scheiden oder sie mit denselben verbinden; und endlich jene wichtige Grenzscheide, welche die Kunstgeschichte von der praktischen Kunstübung trennt, und welche nichts Anderes ist, als eine Strecke jener tiefen Kluft, die allerwärts zwischen Theorie und Praxis verläuft.

In innigster Verwandschaft steht die neuere Kunstgeschichte zunächst mit der classischen Archäologie; sie ist sozusagen nur deren jüngere Schwester, dem Gegenstände nach die Fortsetzung derselben. Mit ihr hat sie die zwiefache Natur der Quellen, die Art der Methode, die letzten Zielpunkte

\footnotetext{
${ }^{19}$ Pseudônimo de Giovanni Morelli (1816-1891), autor de um importante método de atribuição de autoria por meio de indícios indiretos. No Brasil, conhecido, sobretudo, graças à apresentação de Carlo Ginzburg em seu "método indiciário", cf.: GINZBURG, Carlo. Mitos, emblemas, sinais. $2^{a}$ ed. São Paulo: Companhia das Letras, 2007, p. 143-179. (Nota do tradutor)

${ }^{20}$ Esta transcrição baseou-se na edição das Wiener Kunstbriefe, cf.: THAUSING, Moritz. Wiener Kunstbriefe. Leipzig: E. A. Seemann, 1884, p. 1-20. O texto foi mantido em sua configuração original, preservando as diversas variantes do alemão austríaco do século XIX, bem como algumas imprecisões pontuais. As duas notas ao texto são de Moritz Thausing. (Nota do tradutor).
} 
gemein. Durch die nahe Verwandtschaft des Stoffes, durch das Uebergreifen der Formen - insbesondere der architektonischen-aus dem einen Zeiträume in den anderen sind beide Disciplinen sehr aufeinander hingewiesen; ja sie bilden eigentlich blos verschiedene Abschnitte einer und derselben Wissenschaft und werden blos darum auseinandergehalten, weil der Einzelne schwerlich den Anforderungen beider Gebiete ganz zu entsprechen vermag. Denn neben jenen gemeinsamen, mehr innerlichen Eigenschaften stehen ebenso viele äusserliche Verschiedenheiten. Das Quellengebiet der Archäologie ist ein ganz anderes; bei der gemessenen oder doch messbaren Zahl seiner Denkmäler ist auch die Anwendung der Methode eine andere, ungleich intensivere; sie kann es auch sein, denn sie hat an der classischen Philologie eine solide Stütze. Dabei kommt das tiefe Interesse an ihrem Gegenstände der classischen Archäologie sehr zu statten, denn der deutsche Geist ist seit lange gewöhnt, die Wurzeln seiner Kraft im classischen Alterthum zu suchen. So hat denn die Archäologie viel früher, als die neuere Kunstgeschichte ihre Begründung und Bearbeitung gefunden; sie erhielt auch demgemäss etwa um zwei Generationen früher Sitz und Stimme in der Universitas litterarum.

Wie nun die Germanistik und romanische Philologie der classischen nachstreben, wie die neuere Geschichte der des Alterthums, so sucht auch die neuere Kunstgeschichte sich der Archäologie als ebenbürtige Schwester an die Seite zu stellen. Allerdings hat sie dazu erst ihren Anlauf genommen; die erste Generation ihrer Lehrer steht noch rüstig da; ja einer ihrer ersten Begründer, Altvater Schnaase, ist erst im Jahre 1875 vor der Zeit gestorben. Für diesen kurzen Zeitraum und die ungleich weniger günstigen Bedingungen ihrer Existenz hat die junge Wissenschaft genug geleistet, und eine spätere Zeit, die mit mehr Gerechtigkeit auf ihre Anfänge zurückblicken kann, wird dies gewiss anerkennen. Dabei erscheint das Gebiet ihrer Forschung weit ausgedehnt, ja vorläufig fast grenzenlos, der Denkmälervorrath ist überwältigend, der Quellenkunde ist durch die neuere Geschichte und Litteraturgeschichte lange nicht in dem Masse vorgearbeitet, wie durch die Philologie für das Alterthum. Dieser Zustand verlangt eine umsichtige Bearbeitung, eine extensive Anwendung der Methode, wenn die Einheit des Faches nicht durch Einseitigkeit gefährdet werden soll. Dabei ist das allgemeinere Interesse am Cegenstande der neueren Kunstforschung oft mehr hinderlich als förderlich, es hängt mit noch praktischen Fragen, mit der Parteien Hass und Gunst zusammen.

Zuweilen haben sich allerdings auch die ausserwissenschaftlichen Zwecke, die praktischen Nebenrücksichten einzelnen Zweigen der Kunstwissenschaft nützlich erwiesen, z. B. der mittelalterlichen, insbesondere der kirchlichen Archäologie, die so als eine Art romantischer Gegensatz zur classischen Kunstwissenschaft hingestellt wurde. Es gab eine Zeit, in der man es in einer gewissen Unklarheit liess, ob man sich für den Heiligen selbst oder blos für ein Bild begeistere, ob man den 
Reliquienschrein der Reliquie oder des Schreines halber hochhalte. Die mittelalterliche Archäologie ward dadurch stofflich sicher gefördert, nicht aber in ihrer formalen Ausbildung zu einer wissenschaftlichen Disciplin.

Auf anderen Gebieten, insbesondere für die spätere Zeit von der Renaissance an, ist eine vorzugsweise ästhetische Behandlung der Kunstgeschichte bräuchlich geworden. Man gefällt sich da in einer fortwährenden direkten Anknüpfung an ganz allgemeine, mehr oder minder ungeklärte Begriffe, an einen beiläufigen Schönheitskanon, den man, ob eingestanden oder unbewusst, zumeist von der Antike, zuweilen auch von Raphael entlehnt hat. Diese noch immer gar sehr verbreitete Richtung der Kunstschriftstellerei vergleicht sich etwa den verflossenen Phasen der Naturphilosophie auf dem rechtshistorischen und naturwissenschaftlichen Gebiete. Gepflegt wird dieselbe meist durch Künstler oder künstlerisch angelegte Naturen, welche auf einem ähnlichen Wege wie jene, zu einem mehr subjectiven Verständnisse von Kunstformen und Denkmalen gelangt sind. Auf Crund vorgefasster Geschmacksregeln prüfen sie die Kunstwerke nur, um ihnen den entsprechenden Grad ihres persönlichen Wohlgefallens oder Missfallens in möglichst gewählten Worten an den Hals zu schreiben. Zu der Einsicht, dass solche Geschmacksurtheile stets nur relativen Werth haben und sich im Wechsel der Zeiten und Verhältnisse fortwährend und sehr wesentlich ändern, zu dieser Einsicht sind die meisten unserer Kunstschriftsteller entweder nicht durchgedrungen oder sie machen keinen Gebrauch davon.

Wir gelangen hier zu einer anderen Grenze der Kunstgeschichte, zu jener nämlich, wo sich dieselbe mit der Aesthetik berührt und von derselben scheidet. Sehr mit Unrecht wirft man diese beiden Wissenschaften zusammen, denn dieselben sind in Methode und Problem von einander völlig verschieden. Mit der Aesthetik als philosophischer Disciplin hat die Kunstgeschichte nichts gemein, oder doch nicht mehr, als etwa die politische Ceschichte mit der Moralphilosophie, die Physiologie mit der Psychologie, die Naturkunde mit der Metaphysik, d. h. sie liefert der Aesthetik wohl einen Theil ihres Stoffes zur weiteren philosophischen Verarbeitung, ob aber diese davon Gebrauch macht oder nicht, das tangirt die kunstgeschichtliche Forschung keineswegs. Die Kunstgeschichte ist jedenfalls nicht berechtigt, auch ihrerseits in das philosophische Gebiet hinüber oder hinauf zu greifen und ästhetische Formeln oder Ausdrücke irgend eines Systemes zu ihren Zwecken und in ihrer Darstellung zu verwerthen. Sie hat nichts zu thun mit Deduction, mit Speculation überhaupt; was sie zu Tage fördern will, sind nicht ästhetische Urtheile, sondern historische Thatsachen, welche dann etwa einer inductiven Forschung als Materiale dienen können. So wenig also wie die politische Geschichte den Zweck hat, moralische Urtheile zu fällen, so wenig ist der Massstab der Kunstgeschichte ein ästhetischer; derselbe ist überhaupt kein absoluter, sondern blos ein relativer, je nach der auf- oder absteigenden Richtung, welcher die 
Kunstentfaltung einer Epoche folgt. Die Frage z. B., ob ein Cemälde schön sei, ist in der Kunstgeschichte eigentlich gar nicht gerechtfertigt; und eine Frage wie: ob z. B. Raphael oder Michelangelo, Rembrandt oder Rubens das Vollkommenere geleistet haben, ist eine kunsthistorische Absurdität. Ich kann mir die beste Kunstgeschichte denken, in der das Wort "schön" gar nicht vorkommt. Das kunsthistorische Urtheil gründet sich blos auf die durch Forschung und Augenschein festzustellenden Bedingungen, unter denen ein Kunstwerk entstanden ist. Die Frage, in welchem Verhältnisse das Können eines Künstlers zu seinem Wollen, in welchem Verhältnisse beide zu dem von ihm gehandhabten materiellen Stoffe stehen, beantwortet uns allein ein Vergleich mit seinen Zeitgenossen, seinen Vorläufern und Nachfolgern, nicht aber die Anlegung irgend eines allgemeinen, ästhetischen Massstabes.

Die ästhetisirende Behandlung der kaum erst so erfolgreich begründeten Kunstgeschichte ist für die Fortentwicklung, wie für den guten Ruf derselben von grossem Nachtheile gewesen. Denn einmal musste die schnell fertige, so viele Mittelglieder überspringende Beurtheilung und Classification vom Fluche der Unfruchtbarkeit begleitet sein; andererseits war dies summarische Verfahren nicht geeignet, bei ernsthaften Denkern hohe Begriffe von der Methode- und Disciplinfähigkeit des Faches zu erwecken. Es förderte vielmehr die Verbreitung jener Anschauung, nach welcher Kunstgeschichte doch nur eine Art geistiges Lotterbett sei - eine Art Naschwaare, welche die Gefahr geistiger Indigestionen mit sich führt nicht aber eine gesunde geistige Kost, ein Feld schwerer und lohnender Arbeit, gleich allen anderen wissenschaftlichen Gebieten. Und so kam es denn, dass die Kunstgeschichte mit der Aesthetik mehr als nöthig in Zusammenhang gebracht wurde, und dass es uns somit viel mehr noth thut, hier die trennenden Grenzen, die unterscheidenden Merkmale zu betonen, als die Verwandtschaft mit diesem Fache.

Anders steht es um das Verhältniss unserer Wissenschaft zu einem dritten Gegenstande des Universitätsstudiums; ein Verhältniss, auf welches ich den grössten Werth legen muss, nämlich das zur Weltgeschichte des Mittelalters und der neueren Zeit. Bei diesem Verhältniss gilt es, auf die verbindenden Momente mehr Gewicht zu legen als auf die unterscheidenden. Steht die Kunstgeschichte zur Archäologie in dem Verhältnisse einer Fortsetzung, zur Aesthetik in dem einer Vorläuferin oder Vorarbeiterin, so verhält sie sich zur Geschichte, wie eine fortwährende Begleiterin, eine nothwendige Ergänzung, ein unentbehrlicher Theil. Ich fasse da allerdings Geschichte nicht in dem auf Staaten-, Regenten- und Kriegsgeschichte eingeschränkten Sinne, wie er lange Zeit hindurch der allein giltige war und heute noch vielfach vorherrschend ist; sondern in jenem allgemeineren Verstände, der auf das gesammte geistige Leben, auf alle Formen der Cesittung, auf Staat, Religion, Litteratur und Kunst hinzielt. Sie wird auf diesem Wege zur Volksgeschichte, zur Culturgeschichte im guten Sinne, d. h. in 
jenem Sinne, den Böckh auch in seinen allgemeinen Begriff der Philologie gelegt hat. Wenn diese Philologie die Sprachenkunde, die Litteraturkenntniss, die Archäologie und Ceschichte, Antiquitäten und Rechtsalterthümer in sich begreifen soll, was wäre sie dann Anderes, als die Wissenschaft vom geistigen Menschen, als das, was wir Culturgeschichte nennen könnten, wenn dieser Name nicht durch Missbrauch abgenützt wäre? Verschiedene Worte für das gleiche Ziel! Denn trotz aller Widersprüche der historischen Politiker, wird wohl auch die Geschichte immer mehr die Richtung auf eine allseitige Erforschung und Durcharbeitung der überlieferten Culturdenkmäler nehmen - zumal in einer Zeit, deren grösste Staatsmänner auch von ihrem Standpunkte gegen die Trennung der Begriffe Regierung und Volk protestiren und zu dem letzteren auch die Regierenden gezählt wissen wollen. So wird denn andererseits auch die politische Ceschichte das Völkerleben immer mehr in ihren Bereich ziehen müssen, $d$. h. vor Allem die innere Entwicklung jener Nationen, welche sich um die moderne Cultur vornehmlich verdient gemacht haben. Nach diesem letzteren Cesichtspunkte hat ja die Ceschichte ohnedies stets die Grenzen des ihr Erforschungswürdigen abgesteckt. Dies vorausgesetzt, bildet die Kunstgeschichte, insbesondere die des Mittelalters, genau so einen Zweig der neueren Geschichtswissenschaft, wie die Archäologie einen Zweig der sich thatsächlich zur Alterthumswissenschaft erweiternden Philologie - und zwar einen sehr wichtigen und wesentlichen Zweig, sobald es sich einmal um eine richtige Erkenntniss der jeweiligen Culturzustände eines Volkes handelt.

Die besondere Eigenthümlichkeit der Kunstgeschichte, wie andererseits auch die eigenthümliche Schwierigkeit ihrer Behandlung, liegt in der zwiefachen ganz verschiedenen Art der Quellen, aus denen sie ihre Ergebnisse zieht. Einmal sind es schriftliche Nachrichten, als Inschriften, Urkunden, Briefe, Schriftsteller; Zeugnisse also, welche ganz den gewöhnlichen Regeln historischer Kritik unterstehen und derselben auch im gleichen Masse bedürfen, wie die Quellen der allgemeinen und politischen Staatengeschichte. Gegenüber diesen litterarischen Zeugnissen oder Documenten aber steht die andere Gruppe unserer Erkenntnissquelle, die Monumente, die Denkmäler und Kunstwerke, welche zugleich den Hauptgegenstand unserer Forschung bilden. Unbestritten gelten dieselben als das kostbarste Vermächtniss, welches die Vergangenheit uns überliefert hat. Wie die Documente in Worten, so sprechen die Monumente in sichtbaren Formen zu uns, und diese Sprache richtig lesen und verstehen zu lernen, ist die Aufgabe der Kunstgeschichte. Indem sie uns deutliche Bilder vergangener Culturperioden vor's Auge führt, ist sie bereits ein mächtiges Hilfsmittel zu richtiger Erkenntniss und Würdigung derselben. Unsere meisten Vorstellungen und Begriffe sind nun einmal an Eindrücke des Cesichtssinnes geknüpft; sie werden daher von dieser Seite am meisten einer Berichtigung zugänglich - ja auch bedürftig sein. Unsere Kunstdenkmäler geben uns aber nicht blos Abbildungen aus der Vergangenheit, 
eine Illustration der Urkunden, ein Correctiv für unsere rastlose Einbildungskraft, sie geben uns zugleich auch eine untrügliche Kunde von der Art, wie ein vergangenes Zeitalter dachte und fühlte, von der ganzen geistigen Potenz, über welche dasselbe verfügte. Auch aus diesem Gesichtspunkte, und vornehmlich aus diesem, ist die Kunstgeschichte eine Hilfswissenschaft der allgemeinen Geschichte, und zwar eine unentbehrliche. Mit Recht erklärt es der grösste lebende Philologe und Historiker des Alterthums, Theodor Mommsen, für absurd, die Ceschichte eines Volkes zu schreiben, dessen Sprache man nicht verstehe. Nun, die Kunst eines Volkes ist auch eine Sprache; ihre Denkmäler sind wie ragende Meilenzeiger, die den forschenden Blick weit zurückgeleiten den Weg, auf welchem eine Nation durch Jahrhunderte, Jahrtausende von ihrem Cenius geführt worden ist. Ja sie geleiten uns hinauf in Zeiten, in denen die schriftlichen Quellen noch nicht fliessen und die man daher - ich glaube mit Unrecht prähistorische nennt. Und die Sprache dieser ungeschriebenen Zeugnisse ist ideeller, ist unbefangener, freier von blos subjectiven Eindrücken und äusseren Zufälligkeiten, als jene andere in Wort und Schrift. Sie mag schwerer verständlich sein, sie kann aber nicht missverstanden werden. Ist man ihrer einmal mächtig geworden, dann kann sie vor Allem uns Historiker vor dem sonst ja zuweilen berechtigten Vorwurfe schützen, den der Dichter in die Worte kleidete:

\footnotetext{
Was Ihr den Geist der Zeiten heisst, Das ist im Grund der Herren eigner Geist, In dem die Zeiten sich bespiegeln.
}

Ist es nun schon eine Wissenschaft, die Sprache der litterarischen Urkunden, der Documente zu verstehen, dieselben auf ihre Echtheit und Bedeutung zu prüfen, um wie viel mehr wird es einer Wissenschaft bedürfen, in die Unterscheidung und in das Verständniss der Monumente oder Kunstdenkmäler einzudringen. Der Weg dahin wird nothwendig ein langwieriger und beschwerlicher sein, und man sollte darum an die Fortschritte auf demselben keine zu hohen Anforderungen stellen. Nicht als ob unser Fach eine ganz besondere und ungewöhnliche Begabung voraussetzte, wie etwa die Kunstproduction selbst. Die Kunstgeschichte verlangt, meiner Ueberzeugung nach, von ihrem Jünger sicherlich nur jenen Grad allgemeiner Bildung und Sinnesfrische, wie sie auch sonst zur erfolgreichen Cultivirung jedes exacten Wissensgebietes unentbehrlich ist. Und am wenigsten schöpft unsere Wissenschaft ihre Urtheile nach einer sonst nicht gebräuchlichen oder gar geheimen Methode. Die Hindernisse ihres Fortschrittes sind vielmehr ganz äusserlicher Natur; sie liegen zumeist in der nahezu an Unmöglichkeit grenzenden Schwierigkeit, sich die nöthige Uebersicht über den Denkmälervorrath zu verschaffen und die Einzelheiten daraus im Gedächtnisse festzuhalten. Auf der genauen Anschauung der 
Denkmäler beruht aber vor Allem unser Studium. Um zu dieser Kenntniss zu gelangen, bedarf es jedoch keiner besonderen Eingebung oder Divination. Vielmehr ist es nur ein Weg genauer Prüfung und fortwährender Vergleichung, ähnlich demjenigen, den die realsten unserer Wissenschaften, die Naturwissenschaften einzuschlagen pflegen. Cegen diese befinden wir uns nur darum in so grossem Nachtheile, weil die Kunstgegenstände nicht so leicht erreichbar sind wie Naturobjecte und weil es für uns absolut kein Experiment, und am wenigsten ein corpus vile gibt.

Selbstredend gilt Alles, was wir von der zwiefachen Art unserer Erkenntnissquellen sagen, zugleich auch von der Archäologie. Die letztere hat allmählich den gesammten Vorrath der vorhandenen antiken Kunstdenkmäler in den Bereich ihrer Forschung gezogen, und es fällt Niemandem ein, ihre Competenz in diesen Dingen auch nur in Zweifel zu ziehen. Anders steht die Sache bei der neueren Kunstgeschichte. Diese vermag nicht leicht die ungeheuere Masse des sich ihr darbietenden Stoffes zu erschöpfen; sie arbeitet noch mühsam an der Abgrenzung ihres Gebietes, sie ringt erst um die allgemeinere Anerkennung, ja sie kämpft noch für ihr Recht an jener grossen Grenzscheide, die sonst zu Gunsten aller anderen Wissenschaften bereits anerkannt wird, an der Grenze, welche die Theorie und Praxis von einander scheidet. Wer würde nicht lächeln bei dem Gedanken, dass man einem Bildhauer, als solchem, ein Urtheil über die Herkunft oder Originalität einer antiken Sculptur zumuthen oder denselben mit der Aufsicht oder Anordnung einer Sammlung von Sculpturen oder auch nur Gypsabgüssen betrauen wollte? Oder aber, wenn man einen Stempelschneider zum Director einer Münzensammlung machte? Dagegen findet man es an manchen Orten ganz natürlich, dass Maler an der Spitze der Bildergallerien stehen, und aus dem Munde so vieler Gebildeten hört man immer wieder den grossen, schon von Rumohr abgethanen Irrthum, als ob nur der Maler als solcher ein Cemälde zu beurtheilen wüsste ${ }^{21}$. Die Unklarheit über diese Crenzscheide gereicht unserer Wissenschaft zu grossem Nachtheile, nicht blos in der Meinung der Menge, sondern auch in unserer eigenen Thätigkeit. Sie täuscht uns über unsere Rechte sowohl, wie über unsere Pflichten; sie drängt uns von dem gründlichen Studium der Denkmäler ab und lässt Manchen von uns sich in blos litterarischen Combinationen genügen.

Wenn dem wirklich so wäre, dass nur der Kupferstecher über einen alten Stich, nur der Maler über ein altes Gemälde, nur der Elfenbeinschneider über ein Diptychon, nur der Töpfer über eine antike Vase zu

\footnotetext{
${ }^{21}$ C. F. von Rumohr, Italienische Forschungen 1831, III. 148 bis 154 mit dem Schlusse: "Wer denn hat Recht zu entscheiden, wo es das Allgemeine, das rein Menschliche gilt? Nicht der Zunftgenosse als solcher, wie hoch, wie niedrig er im Handwerke stehen möge, sondern der unbefangenste, reinste, besonnenste Mensch, möge er Künstler, möge er dem äusseren Berufe nach sein, was er ist. Den ganzen Werth, die belebende Kraft eines solchen Beifalls, können freilich nur solche Künstler ermessen, denen jemals die Freude zu Theil geworden, durch deutliche Vergegenwärtigung würdiger Aufgaben unbefangen empfängliche Personen zu erfreuen und hinzureissen. Doch lehrt die Geschichte, dass eine verbreitete populäre Empfänglichkeit dieser Art für die Kunst die erste Bedingung einer gedeihlichen Entwicklung, hingegen: eine Kunst blos zur Befriedigung der Künstler, ein unerhörtes Unding ist".
} 
hören wäre, dann allerdings, dann gäbe es gar keine Kunstwissenschaft, keine Kunstgeschichte. Dass diese Annahme aber ganz falsch und unberechtigt ist, muss immer wieder, zumal dort und dann gesagt werden, wo und wenn es gilt, neue Kräfte für unser Fach zu gewinnen. Wie könnte man es denn als Lehrer verantworten, Jemanden zur Nachfolge auf ein so unvollkommenes Wissensgebiet aufzumuntern, das sich nicht einmal - wie man uns weiss machen möchte - von praktischen Uebungen unabhängig machen kann, auf ein Wissensgebiet, dessen letzte und beste Wahrheiten uns ein dem Auge undurchdringlicher Schleier bedecken soll, den zu lüften nur die Hand des Praktikers das Recht hätte? Beruhigen wir uns indessen, so arg ist es um die Kunstgeschichte nicht bestellt und allmählich wird auch alle Welt zu der Einsicht gelangen, dass wohl immer die Hand dem Auge, niemals aber das Auge der Hand nachgegangen ist. Ueber ein altes Gemälde sich bei einem modernen Maler belehren zu wollen, ist nicht minder thöricht, als wenn wir uns über eine alte Urkunde von einem Diplomaten wollten Unterricht ertheilen lassen. Hier wie dort fallen Gegenwart und Vergangenheit völlig auseinander und die Erkenntniss der letzteren bleibt ausschliesslich Sache der Wissenschaft.

Aber mehr noch als das! Praxis und Theorie sind nicht blos auseinander zu halten, sie bilden auch einen sehr entschiedenen Gegensatz zu einander, entsprechend den beiden ganz verschiedenen Wegen, auf welchen der Mensch zum Verständnisse eines Dinges gelangt. Der eine Weg ist der der Nachahmung mittelst einer Summe erlernter Fähigkeiten, der andere ist der der Forschung durch blosse Beobachtung, Prüfung und Vergleichung. Nun ist es wohl unvermeidlich, dass beide Thätigkeiten sich auch hie und da kreuzen, theils sich hemmend, theils auch sich unterstützend; die Ziele ihres Strebens sind aber so verschiedener Natur, dass an eine Uebereinstimmung der Resultate nirgends gedacht werden kann.

Der Künstler bildet sein Auge sozusagen mittelst seiner Hand. Er tastet die Formen ab, indem er sie nachbildet, und erst mittel bar mit Hilfe dieser Art von Tastsinn sieht und beurtheilt er Kunstwerke. Was er durch langjährige Uebung kennen lernt, ist nicht die Kunst überhaupt, sondern seine Kunst, eine ihm ganz eigenthümliche Formenanschauung, die ihn für alle anderen Anschauungen blind oder doch sehr einseitig macht. Schon beim Nachbar ist er nicht mehr zu Hause, um so viel weniger in einer längst entrückten Zeit, aus welcher alle Traditionen, auch die technischen, vollständig abgebrochen sind. Ich spreche hier natürlich nur vom tüchtigen Künstler, der diesem Namen Ehre macht. Von einem solchen denkenden, seiner Ziele bewussten Künstler können wir über sein eigenes Schaffen und sein technisches Verfahren etwas lernen, was dann auch einer allgemeineren, wenn auch veränderten theoretischen Anwendung Fähig sein mag. Solch' ein Künstler hat aber auch in der Regel Besseres zu thun, als um den Preis der Kennerschaft zu buhlen und sich um Genossen oder Vorfahren in seiner Kunstübung sonderlich zu kümmern. Jene mittelmässigen Talente jedoch, welche dies häufiger thun, haben es oft gar nicht bis zu einer eigenen Formenanschauung 
gebracht; sie entbehren somit auch jener subjectiv gefärbten Brille, durch welche sonst Künstler, wenn auch nicht zu richtigen, so doch zu geistreichen oder originellen Kunsturtheilen gelangen; von ihnen können wir gar nichts lernen.

Von den ausübenden Künstlern als solchen sind selbstverständlich jene Männer zu unterscheiden, die es zwar ursprünglich mit der Kunstübung versucht haben, bald aber davon abgekommen sind, um sich fortan blos theoretischen Kunststudien hinzugeben. Dabei werden ihnen ihre praktischen Vorübungen sicher zu statten kommen, keineswegs aber sind dieselben unumgänglich nothwendig. Um ein Werk bildender Kunst geniessen und verstehen zu lernen, bedarf es ja nicht, wie bei einem musikalischen Tonstücke, einer wiederholten Reproduction. Das Bildwerk ist ein-für allemal fertig und verlangt zu seiner Würdigung nichts als aufmerksame Betrachtung. Es ist eine ganz banausische Ansicht, als ob man, um zu einem Urtheil über sichtbare Kunstwerke zu gelangen, es auch mit deren Herstellung versucht haben müsste. Diese sich so gedankenlos fortpflanzende Behauptung enthält ebensowohl eine ungerechte Zumuthung für die producirende Kunstwelt, wie eine Kränkung des allgemeinen Rechtes auf wissenschaftliche Forschung. Indem wir Kunsthistoriker dieses Recht ausdrücklich für uns in Anspruch nehmen, gibt es für uns keine andere Art der Erkenntniss, als die auf dem Wege der Theorie. Unsere Aufgabe istes, nur unser Auge zu bilden, ohne Rücksicht auf eine besondere Schulung der Hand. Wir wollen eben blos sehen lernen.

Dies ist allerdings nicht so leicht, als es den Anschein hat. Der Naturmensch, das Kind empfängt sehr unvollkommene Eindrücke von dem Geschauten. Nicht sowohl die Hand, als das Auge des Menschen ist ursprünglich ungeschickt und Jahrtausende hat es gebraucht, um sich auf dem langsamen praktischen Wege, auf dem Wege der Kunst zu seiner heutigen Empfänglichkeit heranzubilden. Den alten Japanern, Indern oder Iren, welche die menschliche Gestalt ungenügend bildeten und bewegten, fehlte es keineswegs am Ceschick der Hand, denn zahllose Beispiele der feinsten wie der schwersten Arbeit beweisen das Gegentheil. Es fehlte ihnen nur an den Erfahrungen des Auges, welche erst spätere Zeiten nach und nach gemacht haben. Das Menschengeschlecht hat eben erst allmählich sehen gelernt, ganz so wie es allmählich feiner hören und deutlicher sprechen lernen musste. Und zwar hat es auf jedem der beiden grossen, uns zunächst angehenden Culturgänge, auf dem des Alterthums und dem der neueren Zeit, fast wieder von vorne damit anfangen oder doch neue Anläufe dazu nehmen müssen. Ein für uns besonders lehrreiches Beispiel liefert die Entwicklung des Farbensinnes. Wie lange dauerte es, ehe der Mensch nur die Farben des Regenbogens sehen, respective von einander unterscheiden lernte! Weder die Rigveda, noch der Zendavesta, noch die Bibel kennen z. B. die blaue Farbe. Blau fällt dort überall noch mit dem Begriff von Schwarz zusammen, und das Gleiche gilt angeblich von dem Worte kyaneos bei Homer, 
obwohl unser Cyan daher stammt, hat doch das ganze Alterthum kein Wort für das reine Blau besessen, da ja auch cœruleus sich nicht dafür festhalten lässt. Nicht viel besser steht es um die Bezeichnung der grünen Farbe, welche die ältesten Sanskrit- und Zendurkunden gleichfalls nicht kennen und die im griechischen chlóros vom Celb óchros kaum zu trennen ist. Da es nun doch an Veranlassungen, Himmel und Meer blau, Bäume und Fluren grün zu nennen; nicht fehlen konnte, so haben wir es hier offenbar mit einer theilweisen Farbenblindheit zu thun, die nur aus dem Mangel genügender Unterscheidung hervorgehen konnte; gerade so wie die Beschränkung der Ursprachen auf die drei Vocale a, i, u im Gegensatze zu einer so reichen Ausbildung des Vocalismus in einer Sprache wie das heutige Englisch nur aus der mangelhaften Ausbildung des Cehöres zu erklären ist ${ }^{22}$.

Diese langsame Entwicklung des Farbensinnes findet ihre Analogie auch in der späten Entdeckung der Harmoniegesetze auf dem musikalischen Cebiete. Und darum konnte die Malerei sowohl, als die Musik erst in der neueren Zeit zu ihrer Blüthe gelangen. Beide sind ganz specifisch moderne Künste. Welch' lange Kraftproben von Gesicht und Gehör mussten vorangehen, bevor ein Cemälde von Rembrandt, eine Symphonie von Beethoven entstehen und genossen werden konnten! Die Alten konnten von solchen Höhepunkten beider Kunstentwicklungen platterdings gar keine Ahnung haben; so wie hinwiederum wir ihren bescheidenen Anfängen in diesen Richtungen heute verständnisslos gegenüberstehen. Und darin liegt wohl sicher auch der Grund dafür, dass wir uns vom Standpunkte unserer ausgebildeten und geläuterten Farbenempfindung mit der schlichten Polychromie der Alten niemals werden befreunden können.

So vollzog sich denn in einer Jahrtausende alten Entwicklung die Vervollkommnung des menschlichen Gesichtssinnes. Es geschah im Dienste der Kunst und zu ihren Zwecken, ob dieselbe auch zuweilen in Stillstand und Niedergang begriffen war. Es geschah zu Zeiten, da es keine Kunstgeschichte gab, und die Kunst wird auch weiterhin nach unerforschten ewigen Gesetzen auf- und niedergehen; unbeirrt durch unsere wissenschaftlichen Bestrebungen. Wir Kunsthistoriker sind auch weit entfernt, uns irgend eine Einflussnahme auf die Kunstübung anzumassen. Nachdem aber einmal das Bedürfniss nach der Erforschung unserer Kunstvergangenheit unabweisbar geworden ist, gönne man uns auch die freie Bewegung auf dem uns anheimfallenden historischen Felde. Wir wollen dies Feld ausreuten, ebnen und bebauen auch den Künstlern zu Liebe, die sich ja so gerne darin ergehen. Ihnen wäre es denn doch ein

\footnotetext{
22 L. Geiger, Zur Entwicklungsgeschichte der Menschheit, Stuttgart 1840, S. 45 ff. - Dazu stimmt, dass Aristoteles den Regenbogen dreifarbig nennt, nämlich roth, gelb, grün (wie auch die Edda denselben als eine dreifarbige Brücke erklärt), während Xenophanes 200 Jahre früher in der Iris blos eine purpurne, röthliche und gelbliche Wolke sieht. Demokrit und die Pythagoräer nahmen vier Grundfarben an: schwarz, weiss, roth und gelb, eine Anschauung, welche lange Geltung behielt, und Nachrichten bei Cicero, Plinius und Quinctilian wollen uns verbürgen, dass die griechischen Maler noch bis auf die Zeit des Alexander nur eben jene vier Farben angewendet haben.
} 
unentdecktes Land geblieben, hätte sich die Theorie seiner nicht bemächtigt. Ein Jahrhundert lang zogen ja die Künstler nach Italien, vorbei an der Antike und dem Cinquecento, um unbelehrt und unbekehrt wiederzukommen, bis ihnen Winckelmann das Alterthum entdeckte, Rumohr die Renaissance wiederfand.

An das Auge des Kunsthistorikers werden eben ganz andere, viel allgemeinere und umfassendere Anforderungen gestellt, als an das des Künstlers. Unser Sehen muss schon darum ein ganz anderes sein, weil es ausschliesslich die Erkenntniss des Cegenstandes zum Zwecke hat, ohne jede Beengung durch vorgefasste Formenanschauungen und ohne alle auf Nachbildung und praktische Ausführung gerichtete Nebenabsichten. Um zu einem Ziele zu gelangen, muss man doch mindestens entschieden darauf losgehen. So nebenbei wird man es doch nicht zu erreichen vermeinen, auch wenn es minder hoch gesteckt wäre. Dass aber seine Erreichung auf unserem rein theoretischen Wege möglich ist, dafür liefert uns unsere Wissenschaft bereits Beweise genug. Und bis zu welchem hohen Grade der Sicherheit sich unter günstigen Umständen der Kennerblick ausbilden kann, dafür haben wir in einzelnen bevorzugten Naturen erhebende Beispiele vor uns.

Lassen wir uns daher durch die krausen Ausdrücke und Anrufungen, mit denen Kunstwerke regalirt zu werden pflegen, nicht verblüffen. In gewissem Sinne muss allerdings das Individuum den Entwicklungsgang der ganzen Race wiederholen, und in diesem Sinne muss auch unser Auge, der gesammten Kunstentfaltung der Vergangenheit folgend, sein Sehvermögen zu möglichster Feinheit ausbilden. Wir stehen da vor einer grossen Aufgabe, nicht abervor einer Unmöglichkeit. Es gibt keine Seele, keinen Ceist, keine Empfindung - und wie die Worte alle heissen - in einem Kunstwerke, die nicht durch sichtbare, ganz concrete Formen in dasselbe hineingetragen wären und die darum nicht auch auf demselben klaren und deutlichen Wege aus demselben herauszusehen, herauszulesen wären. Nur muss freilich diese Formensprache der Kunst, gleich allen Sprachen, erst mühsam erlernt werden. Nach Massgabe der Begabung und der Celegenheit zur Uebung wird es vielleicht nicht Jedermann zur rechten Meisterschaft darin bringen. Wenn es uns aber gelingt, und in dem Grade, in welchem es uns gelingt, hört auch die Handschrift jedes echten Künstlers auf, uns ein Räthsel zu sein. Wir mögen dann getrost vor sein Werk hintreten, eingedenk der schönen Worte, welche uns ein mir so hochwerther Freund und Kunstkenner wie Iwan Lermoliew zuruft:

Ein Kunstwerk wird Dir stets eine richtige Antwort geben, wenn Du es zu befragen verstehst. Bleibt es Dir die Antwort schuldig, so ist es nur ein Zeichen, dass entweder Deine Frage unverständig war, oder dass das Werk überhaupt keine Sprache spricht,

d. h. dass es kein wahres Kunstwerk ist. 